\title{
Analysis of Energy Consumption Indicators for Non-OECD Countries
}

\author{
Ahmed Adamu
}

\begin{abstract}
This paper studies three major indicators of energy consumptions for non-OECD countries, with a view to identifying the major cause of the increasing energy consumption among the non-OECD countries. Multiple regressions using VAR model was used in estimating these relationships. The indicators used are total electricity, GDP and population. It was observed that high level of economic output designates low energy consumption in non-OECD countries due to economic of scale,this is confirmed with high level of significance. However, increase in electricity consumption was observed to cause increase in the total energy consumption in these countries. Population was also found to have negative relationship with total energy consumption in these countries, because there are relatively low energy consumption compare to the population of these countries, where low energy consumption is associated with high population. Therefore, these countries shall all enact energy policies that encourage efficiency on how people use the energy, ranging from electricity consumption, use of appliances as well as the mode and type of transportation and fuel respectively. There should also be improvement in energy per-capita accessibility among the non-OECD nations. Similarly the level of economic output shall be increased to achieve low energy intensity.
\end{abstract}

Index Terms-Electricity consumption, OECD, non-OECD, total energy consumption, population, GDP, efficiency, and vector auto-regression model (VAR).

\section{INTRODUCTION}

Global concern on the security of future energy supply has triggered development of new energy sources and applications of efficiency techniques in energy production and consumption. This has not significantly affected the pattern of the energy consumption globally [1]. Similarly, rising worries about the climate change caused by the increasing energy consumption led to the call for the immediate reduction of energy consumption through efficiency and conservation. However, some of the efficiency techniques and new sources of energy require huge capital investment and long time before implementation, therefore the need to study the pattern of the energy demand became imperative in order to identify the major cause of the demand growth [2].

In 2010 Non- OECD (Organization for Economic Co-operation and Development) countries consumed $56 \%$ of the global total energy consumptions [3]. This is more than the OECD countries' energy consumption share of $44 \%$. Despite the low share of the OECD countries' energy consumption, the level of renewable energy growth and

Manuscript received May 25, 2013; revised September 15, 2013.

Ahmed Adamu is with the Newcastle University, United Kingdom (e-mail: a.adamu@newcastle.ac.uk,ahmadadamu@yahoo.com). deployment of efficiency techniques in these countries is growing faster compare to non-OECD countries [4]. Therefore, the non-OECD countries pose more threat to the global environmental concern especially in the future, due to the exponential population growth, pattern of energy consumption and emerging economies among these countries. This underlines the significance of identifying the major energy consumption indicators in the non-OECD countries, so that efficiency and energy intensity can be applied and reduced respectively. Increase in total Energy consumption can be triggered by the level and manner ofhousehold and industrial sectors consume the energy. Households are identified to be one of the major indicators of energy demand changes. Providing information and feedback on energy efficiency could help in reducing the level of energy consumption in that sector [5].

Similarly, providing an energy consumption transparency strategy, where households can track and compare their previous energy consumptions can help to encourage the households in applying efficiency [6]. However, after realizing the fact that households contribute a lot to thecontinues increase in global energy demand, efforts were made to maximize households energy savings, but that has not made significant effect. It was suggested that deeper analysis should be carried out to understand the factors influencing the household energy consumption. It was observed that the level of income of households determine the level of energy consumption [7].

However, industrial sector is considered to consume more energy than households due to the energy intensity of the sector. Decomposing the aggregate energy demand of the sector can give an idea of the major specific influential factors responsible for the energy demand increase in the sector [8]-[9]. According to International Energy Agency (IEA) 2010 report, six energy demand indicators were identified as follows.

1) Electricity consumption

2) GDP

3) Population

4) TPES/GDP (Total primary energy supply per GDP)

5) Electricity consumption/GDP

6) Electricity consumption/population

The IEA 2010 reports recognized the above energy indicators as influential energy demand drivers. Starting with population, OECD countries had 1.2 billion population and no-OECD countries' population had 5.6 billion in 2010 , which gives the ratio of $18 \%$ and $82 \%$ share of the world population for the OECD and non-OECD countries respectively. This could be the reason why non-OECD countries consume higher energy (56\% of the global energy consumption) as mentioned earlier. Considering the level of 
economic activity of the two cluster countries, the OECD countries' GDP monetary value was 37 billion US dollars in 2010, while that of the non-OECD was 31 billion US dollars in the same year. This indicates more efficiency in the OECD countries, since despite their lower energy consumption, yet they recorded higher GDP[3].

From the same report, electricity consumption per GDP in the OECD countries was $\$ 0.27$ per kilowatts hour $(\mathrm{kWh})$ which is per less than that of the non-OECD countries, which had $\$ 0.71$ per $\mathrm{kWh}$. This shows the level of energy efficiency in the OECD countries. That is why, efficiency in the nonOECD countries is more desirable, hence the need to study the major indicators of energy consumption in these countries.

This paper will adopt three parameters to empirically prove or identify the major causes of the energy demand changes in the non-OECD countries with a view to suggesting the proper measures to ensure efficiency and reduction in energy demand in the these countries. The three parameters are the total electricity consumption, gross domestic production (GDP), and population.

The paper is structured in the following format. The next Sectior will present a brief review of related literature, Sectior III will introduce the methodology, assumptions and data to be used in the multiple regression analysis using VAR Sectior IV will present and analyze the results and Sectior V will be the conclusion.

\section{BRIEF LITERATURE REVIEW}

Katircioglu et al. (2013) studied the relationship between energy consumption of G7 countries with income and international trade. They observed these variables to be influencing the level of energy demand in these countries.[10] In another related research by Akinlo A. (2008) who studied the causal effect of energy consumption on the economic performances of eleven sub-Saharan African countries. Using Autoregressive distributed lag, he found that energy demand is positively correlated with economic growth in only seven of these countries. Using another test (Granger causality test) he found that there is bidirectional relationship between energy demand and economic growth in only three of these countries. He further discovered that economic growth granger cause energy consumption in two of these countries. In another set of two countries, he discovered neutrality of this relationship. Similarly, absent of any relationship is observed in another set of three countries. He suggested a unique energy policy peculiar to each country's nature of the relationship between energy demand and economic growth [11].

Al-Iriani (2006) studied the cause of energy demand in six countries of the Gulf Cooperation Council (GCC) using panel cointegration and causality techniques; he discovered that there is unidirectional causality from GDP to energy consumption in these countries. His study also reveals no supporting evidence for hypothesis that there is positive correlation between energy consumption and GDP in these countries [12]. However, this kind of correlation was empirically confirmed in six central American countries in a study by Apergis and Payne (2009), who found causality from energy consumption to GDP in these countries both at short-run and long-run [13]. Another study by Chiou-Wei et al (2008) studied the causality between the GDP and energy consumption among some selected Asian countries and United State (US), they found neutral causality for the US, and unidirectional causality from GDP to energy consumption in only two of the Asian countries. They also found that energy consumption affects GDP in only four of this countries [14].

Income per-capita is another influential factor affecting the level of energy consumption as found by Joel (2004), he also discovered that the level of population growth determine the efficiency of energy use. Highly population density towns can have less energy per-capita compare to the low populated areas. This depends on the local conditions and deficient regulatory policies. High population can equally cause high energy demand [15]. Allan Mazur (1994) studied the influence of population and per-capita energy consumption on the overall energy consumption. He found that population is not influencing energy consumption in the short-run but in the long-run [16].Most of the literature consulted have not studied the combination of electricity consumption, GDP and population as factors influencing energy demand in non-OECD countries, which is what this paper aims to achieve.

\section{Methodology And Data}

Equation 1 represent the multiple regression model to be tested using Vector Auto-regression model (VAR) to determine the coefficients of the three major parameters considered to be influencing increase in the total energy demand in non-OECD countries. The choice of VAR was made after testing the possibility of cointegration among the variables, and we discovered that, they are not correlated, and then we opted for VAR rather than Vector Error Correction Model (VECM).

$$
T E C=a_{0}+a_{1} E L C+a_{2} G D P+a_{3} P O P+\mu
$$

where TEC is the total energy consumption, ELC is total electricity consumption, GDP is the gross domestic production, POP is the population and $\mu$ is the error term.

The data used for this research is sourced from the International Energy Agency (IEA) through economic and social data services (ESDS), the time series data is used from 1994 to 2010. The raw data is presented in Table I, which is later summarized in Fig. 1. The data is mainly for the whole non-OECD countries cumulative. Electricity consumption is measured in Terawatts hour, GDP is measured in monetary value based on the 2005 purchasing power parities (PPP) of the US dollars, and population is measured in millions.

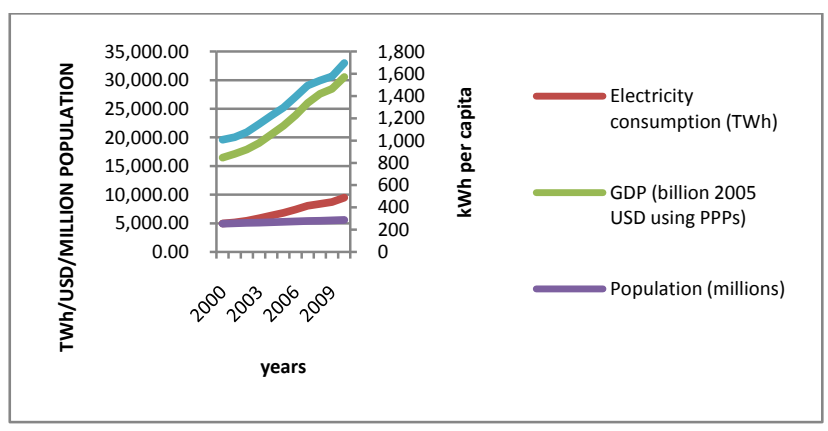

Fig. 1. Graphical illustration of energy demand indicators' trend among non-OECD countries 
TABLE I: TRENDS OF NON-OECD COUNTRIES ENERGY DEMAND

\begin{tabular}{|r|r|r|r|r|}
\hline year & ELC & $\begin{array}{l}\text { GDP (billion } \\
\text { 2005 USD } \\
\text { using PPPs) }\end{array}$ & $\begin{array}{l}\text { Population } \\
\text { (millions) }\end{array}$ & $\begin{array}{l}\text { Total energy } \\
\text { consumption } \\
\text { (TJ) }\end{array}$ \\
\hline 1994 & 3992.647 & 12872.15 & 4495.909 & 122172376 \\
\hline 1995 & 4141.781 & 13437.74 & 4566.879 & 125085574 \\
\hline 1996 & 4304.727 & 14076.98 & 4638.106 & 125323216 \\
\hline 1997 & 4442.013 & 14729.87 & 4709.739 & 126555844 \\
\hline 1998 & 4538.918 & 15013.79 & 4780.796 & 127386091 \\
\hline 1999 & 4690.414 & 15590.7 & 4850.995 & 128848567 \\
\hline 2000 & 4958.215 & 16467.79 & 4921.147 & 132404893 \\
\hline 2001 & 5146.984 & 17128.33 & 4989.897 & 134675259 \\
\hline 2002 & 5442.925 & 17899.6 & 5057.173 & 137724851 \\
\hline 2003 & 5881.275 & 19021.15 & 5123.867 & 144668274 \\
\hline 2004 & 6354.876 & 20508.38 & 5190.295 & 154078927 \\
\hline 2005 & 6809.35 & 22025.09 & 5254.257 & 160744478 \\
\hline 2006 & 7412.71 & 23854.6 & 5320.959 & 168287308 \\
\hline 2007 & 8054.168 & 26003.33 & 5387.637 & 176410400 \\
\hline 2008 & 8394.022 & 27590.18 & 5455.225 & 181436546 \\
\hline 2009 & 8702.317 & 28479.15 & 5523.526 & 184865096 \\
\hline 2010 & 9492.3 & 30550.47 & 5593.178 & 193896732 \\
\hline
\end{tabular}

To test whether our variables are stationary or not, we use correlogram test. The variables both appeared non-stationary at level. The graph presentation of our non-stationary variables is presented in appendix Fig. 2- Fig. 5. However, our variables appeared stationary after conversion to first difference. This means, all our variables depend on their value in previous one time period. The graph of these stationary data is presented in appendix Fig. 6- Fig. 9. Therefore, we will be using the first differences of our variables in the VAR models as follows:

$$
\mathrm{D}(\mathrm{TEC})=\alpha_{0}+\alpha_{1} \mathrm{D}(\mathrm{ELC})+\alpha_{2} \mathrm{D}(\mathrm{GDP})+\alpha_{3} \mathrm{D}(\mathrm{POP}) \mu
$$

For easy handling, we modified our model, where $x_{1}$ represents $\mathrm{D}(\mathrm{ELC}), x_{2}$ represents $\mathrm{D}(\mathrm{GDP}), x_{3}$ represents $\mathrm{D}(\mathrm{POP})$ and $Y$ for $\mathrm{D}$ (TEC). The model is modified as follows:

$$
Y=E C=\alpha_{0}+\alpha_{1} X_{1}+\alpha_{2} X_{2}+\alpha_{3} X_{3}+\mu
$$

Now we are ready to run our VAR model so as to estimate the coefficients of our variables. This will help us know the direction and significance of relationship between each of the independent variables and the dependent variable. The summary of the VAR result is presented in Table II.

\section{DISCUSSION OF THE RESULT}

From our result in Table II, we can derive our final VAR model as follows:

$Y=-0.259249+27653.28 X_{1}-7204.561 \mathrm{x}_{2}-971342.7 X_{3}+$ 71029080
TABLE II: VAR RESULTS

Vector Autoregression Estimates

Date: 06/02/13 Time: 02:58

Sample (adjusted): 19962010

Included observations: 15 after adjustments

\begin{tabular}{|c|c|c|c|c|}
\hline & $\mathrm{Y}$ & $\mathrm{X} 1$ & $\mathrm{X} 2$ & $\mathrm{X} 3$ \\
\hline \multirow[t]{3}{*}{$\mathrm{Y}(-1)$} & -0.259249 & $-2.89 \mathrm{E}-05$ & $-7.02 \mathrm{E}-05$ & $-6.17 \mathrm{E}-07$ \\
\hline & $(0.38270)$ & (3.5E-05) & $(8.2 \mathrm{E}-05)$ & (2.8E-07) \\
\hline & {$[-0.67743]$} & {$[-0.81593]$} & {$[-0.85499]$} & {$[-2.18545]$} \\
\hline \multirow[t]{3}{*}{$\mathrm{X} 1(-1)$} & 27653.28 & 1.412397 & 5.013362 & -0.000284 \\
\hline & $(9447.38)$ & $(0.87566)$ & $(2.02575)$ & $(0.00697)$ \\
\hline & [ 2.92708] & [ 1.61295$]$ & [ 2.47482] & {$[-0.04075]$} \\
\hline \multirow[t]{3}{*}{$\mathrm{X} 2(-1)$} & -7204.561 & -0.326688 & -0.814558 & 0.002227 \\
\hline & (2285.96) & $(0.21188)$ & $(0.49017)$ & $(0.00169)$ \\
\hline & {$[-3.15165]$} & {$[-1.54185]$} & {$[-1.66180]$} & [ 1.32068$]$ \\
\hline \multirow[t]{3}{*}{$\mathrm{X} 3(-1)$} & -971342.7 & -70.18486 & -113.8945 & 0.546522 \\
\hline & (331398.) & (30.7166) & (71.0599) & $(0.24451)$ \\
\hline & {$[-2.93104]$} & {$[-2.28491]$} & {$[-1.60280]$} & [2.23519] \\
\hline \multirow[t]{3}{*}{$\mathrm{C}$} & 71029080 & 5182.323 & 8510.179 & 31.32960 \\
\hline & $(2.4 \mathrm{E}+07)$ & $(2200.81)$ & (5091.35) & $(17.5187)$ \\
\hline & [2.99142] & [ 2.35474] & [ 1.67150$]$ & [ 1.78835$]$ \\
\hline R-squared & 0.839612 & 0.680456 & 0.789781 & 0.821557 \\
\hline Adj. R-squared & 0.775457 & 0.552639 & 0.705694 & 0.750180 \\
\hline Sum sq. resids & $2.22 \mathrm{E}+13$ & 190851.4 & 1021403. & 12.09306 \\
\hline S.E. equation & 1490474. & 138.1490 & 319.5939 & 1.099684 \\
\hline F-statistic & 13.08719 & 5.323658 & 9.392384 & 11.51008 \\
\hline Log likelihood & -231.4622 & -92.16808 & -104.7489 & -19.66844 \\
\hline Akaike AIC & 31.52829 & 12.95574 & 14.63318 & 3.289125 \\
\hline Schwarz SC & 31.76430 & 13.19176 & 14.86920 & 3.525142 \\
\hline Mean dependent & 4587411. & 356.7013 & 1140.849 & 68.41993 \\
\hline S.D. dependent & 3145388. & 206.5468 & 589.1135 & 2.200161 \\
\hline \multicolumn{2}{|c|}{$\begin{array}{l}\text { Determinant resid covariance } \\
\text { (dof adj.) }\end{array}$} & $1.27 \mathrm{E}+20$ & & \\
\hline \multicolumn{2}{|c|}{ Determinant resid covariance } & $2.50 \mathrm{E}+19$ & & \\
\hline \multicolumn{2}{|l|}{ Log likelihood } & -420.1342 & & \\
\hline \multicolumn{2}{|c|}{ Akaike information criterion } & 58.68456 & & \\
\hline \multicolumn{2}{|l|}{ Schwarz criterion } & 59.62863 & & \\
\hline
\end{tabular}

Standard errors in ( ) \& t-statistics in [ ]

ELC

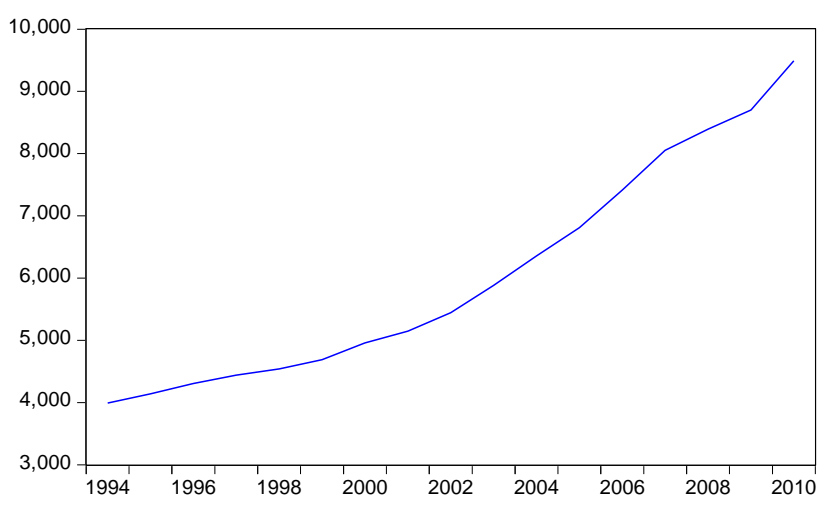

Fig. 2. Non-stationary ELC at level.

Now we can see the direction of relationship between each of the independent variables and the dependent variable. Starting with the Electricity consumption, its relationship with total energy consumption is positive, meaning that, high electricity consumption indicates high energy consumption in non-OECD countries. But, total energy consumption is negatively related to GDP, meaning that higher GDP indicates lower consumption of energy in non-OECD countries, this could be attributed to the resulting low energy 
intensity as more products are produced in a given period of time. Similarly, our model estimated a negative relationship between population and total energy consumption. This could be as a result of low energy per-capita when the population is high and the fact that most of the non-OECD countries have low energy per-capita. Increase in population does not guarantee increase in energy demand, since the same quantity of energy supply can still be sufficient despite the increase in population. Now we will evaluate the significance of each of the variables before making the final conclusion.

GDP

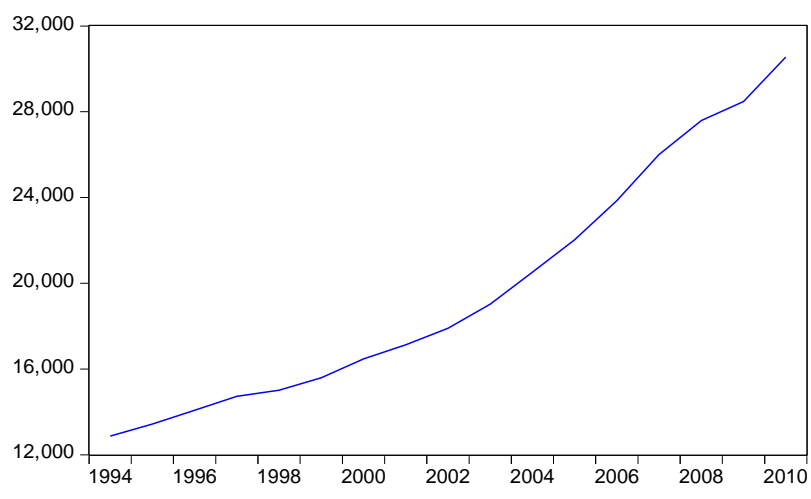

Fig. 3. Non-stationary GDP at level.

POP

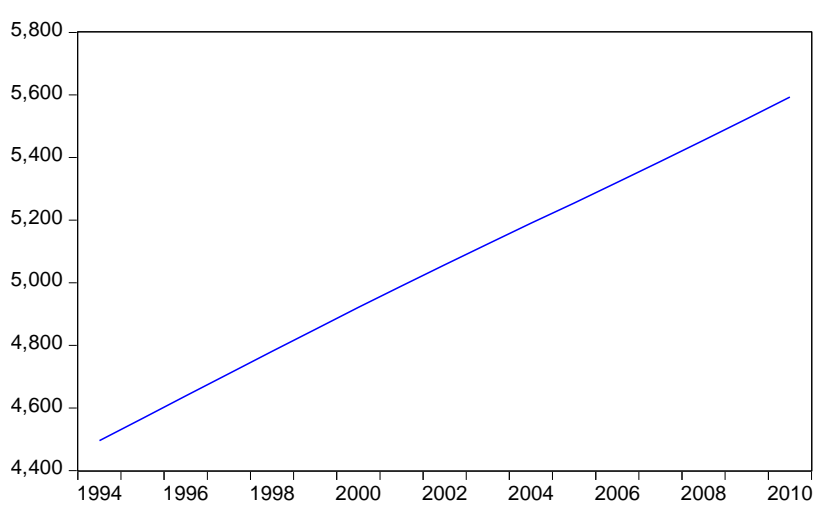

Fig. 4. Non-stationary data of POP at level.

TEC

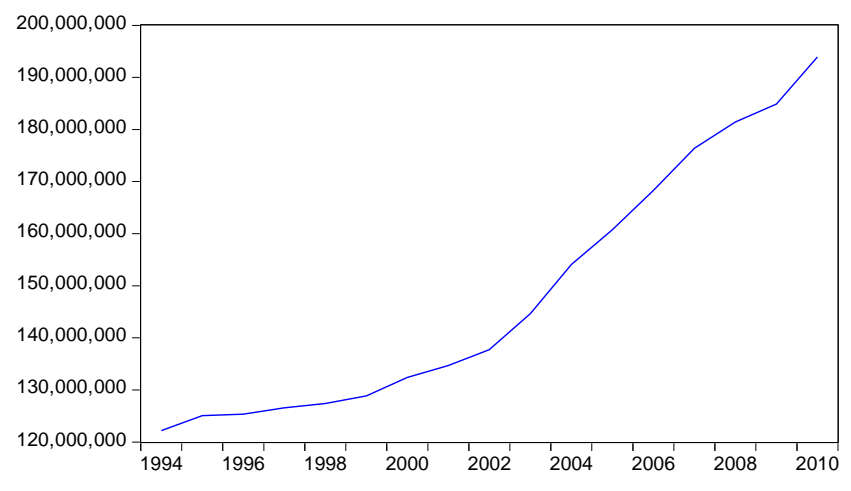

Fig. 5. Non-stationary data of TEC at level.

First, we need to know the probability value of each of the identified coefficients. To do that, we generated the following system equation.

$Y=C(1) \times Y(-1)+C(2) \times X 1(-1)+C(3) \times X 2(-1)+C(4) \times X 3(-1)+$ $C(5)$
The coefficients are now represented by $C(1), C(2), C(3)$, $C(4)$ and $C(5)$ for intercept, electricity consumption, gross domestic production, population and the error term respectively. We will now use the ordinary least square to test the significance of each of these variables in explaining the dependent variable. The variables are lagged by one period.

From the result we observed the probability value of each of the coefficients. Starting with $C(1)$ which is the coefficient of the intercept, which was already identified to be -0.259249 , its probability value is $50.20 \%$ present which is more than the level of significance of 5\%. Therefore, we can reject the null hypothesis that says that intercept is a significant factor in explaining the dependent variables.

Electricity consumption is observed to be very significant in explaining the level of energy consumption in non-OECD countries. The probability value of ELC coefficient is less than $1 \%$, which is less than the level of significance. Therefore, we can't reject the null hypothesis that says that Electricity consumption is a significant factor in determining the level of energy consumption in non-OECD countries.

$\mathrm{X} 1$

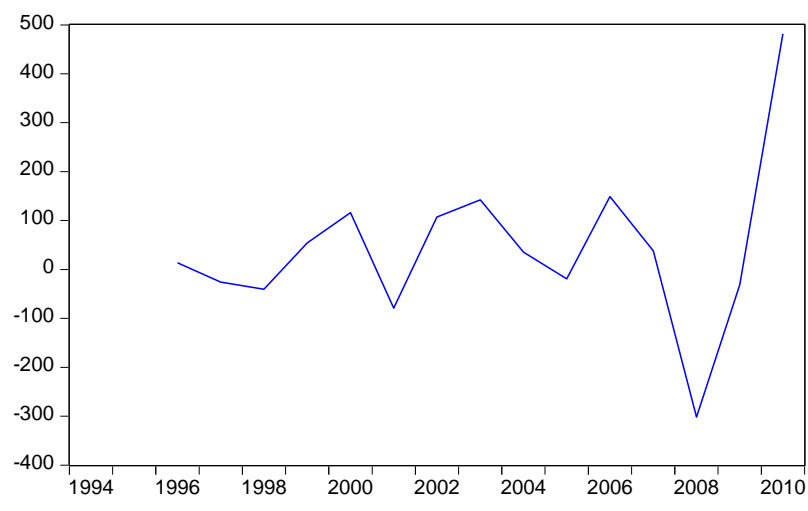

Fig. 6. Stationary data of ELC at second difference.

$\mathrm{X} 2$

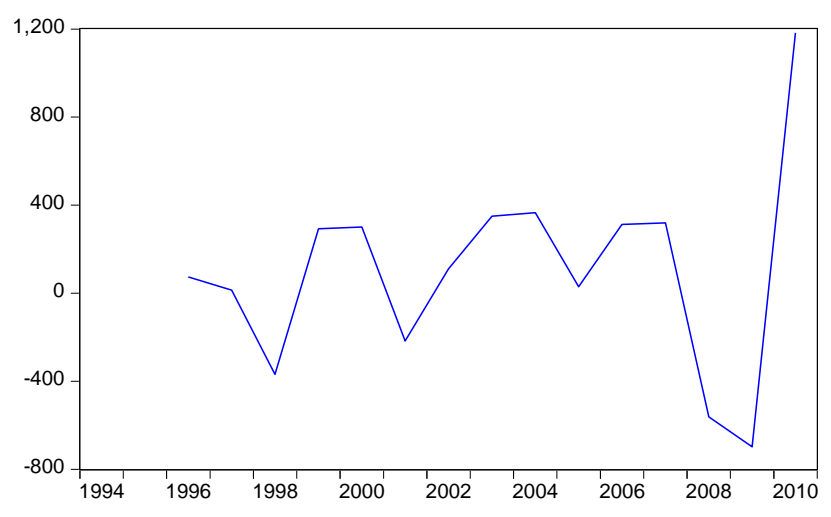

Fig. 7. Stationary data of GDP at second difference.

Based on our VAR result in Table II, we established that there is negative relationship between the level of energy consumption and GDP growth. This is confirmed to be significant after testing the significance of its coefficient using OLS tesst, which reported a $p$ value of less than $1 \%$. This tends to satisfy the law of economic of scale, where operational efficiency is improved with increasing scale, leading to lower average cost. Therefore, increase in GDP does not guarantee increase in energy consumption. 
X3

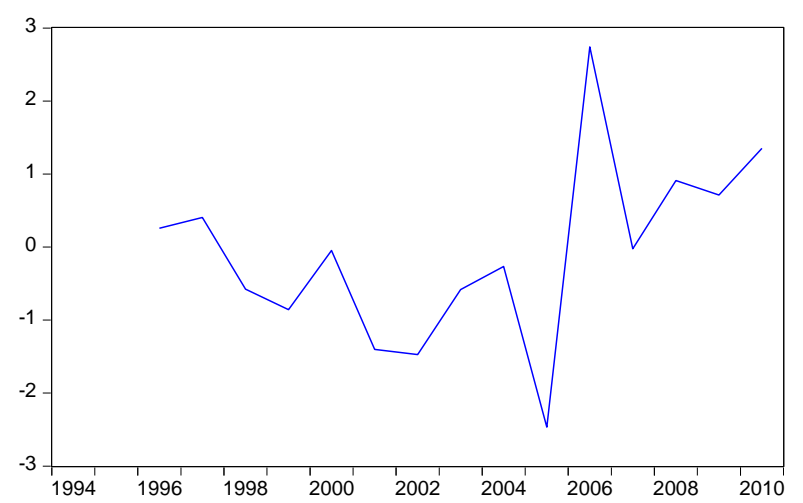

Fig. 8. Stationary data of POP at second difference.

Y

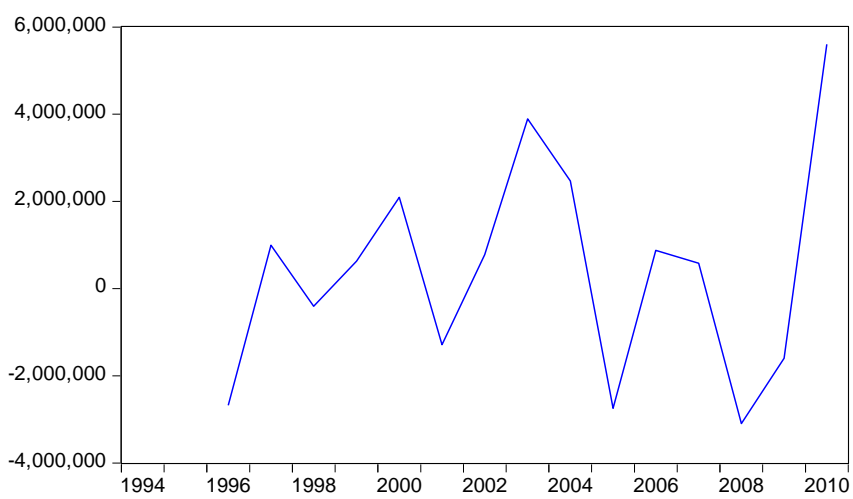

Fig. 9. Stationary data of TEC at second difference.

However, population is observed to be negatively related with total energy consumption in non-OECD countries, and in our test of significance, we found that population is a significant factor in explaining the level of energy consumption in these country. The error term is also significant in explaining the dependent variable.

TABLE III: VIABILITY TEST OF THE MODEL

\begin{tabular}{|c|c|c|c|c|c|}
\hline \multicolumn{5}{|c|}{ VAR Residual Portmanteau Tests for Autocorrelations } & \\
\hline \multicolumn{6}{|c|}{ Null Hypothesis: no residual autocorrelations up to lag h } \\
\hline \multicolumn{6}{|c|}{ Date: 06/02/13 Time: 03:15 } \\
\hline \multicolumn{6}{|c|}{ Sample: 19942010} \\
\hline \multicolumn{6}{|c|}{ Included observations: 15} \\
\hline Lags & Q-Stat & Prob. & Adj Q-Stat & Prob. & df \\
\hline 1 & 8.790105 & NA* & 9.417970 & NA* & $\mathrm{NA}^{*}$ \\
\hline 2 & 21.47289 & 0.8413 & 24.05196 & 0.7264 & 29 \\
\hline 3 & 26.41506 & 0.9877 & 30.22967 & 0.9552 & 45 \\
\hline 4 & 42.47562 & 0.9659 & 52.13042 & 0.7836 & 61 \\
\hline 5 & 52.66925 & 0.9846 & 67.42088 & 0.7740 & 77 \\
\hline 6 & 66.08382 & 0.9844 & 89.77850 & 0.5753 & 93 \\
\hline 7 & 71.59267 & 0.9978 & 100.1076 & 0.7170 & 109 \\
\hline 8 & 82.45286 & 0.9988 & 123.3794 & 0.5242 & 125 \\
\hline 9 & 88.01779 & 0.9999 & 137.2917 & 0.5726 & 141 \\
\hline 10 & 97.20562 & 1.0000 & 164.8552 & 0.3179 & 157 \\
\hline 11 & 99.32437 & 1.0000 & 172.8006 & 0.4900 & 173 \\
\hline 12 & 102.2455 & 1.0000 & 187.4062 & 0.5191 & 189 \\
\hline
\end{tabular}

*The test is valid only for lags larger than the VAR lag order.

df is degrees of freedom for (approximate) chi-square distribution

Now we will test the viability of our model to see if there is presence of residual correlation or bias estimation. To do this we used Portmanteau Autocorrelation test using 12 lags, and we found that our model is viable based on the data obtained for these countries. Summary of this result is presented in table 3 . The null hypothesis says that the model is not viable. Now with all our $p$ values above the level of significance, we can reject this hypothesis and confirm the viability of our model.

\section{CONCLUSION}

From our VAR model in equation (4), we can agree that the selection of our parameters is sufficient to explain the cause of any change in total energy consumption in non-OECD countries. First, electricity consumption is the major significant indicator with high level of significance. So, if our target is to reduce energy consumption among the non-OECD countries, then we can reduce or ensure efficiency in electricity consumption. For GDP, we can empirically confirm negative correlation between GDP and energy consumption in these countries. This explains why the OECD countries have lower energy consumption than the non-OECD countries, despite their higher GDP. Therefore, increase in the GDP of non-OECD countries does not guarantee increase in energy consumption. The multiplier effect is not proportionate, meaning that an increase in GDP does not cause equal increase in energy consumption. This also proved the theory of economic of scale that says that producing more units of outputs reduces the average costs of production. Population also has negative relationship with the total energy consumption in non-OECD countries, because there are low energy consumption compare to the population of these countries, where low energy consumption is associated with high population. This confirms the findings of Joel (2004), who found that highly population density towns can have less energy per-capita compare to the low populated areas. The result of this paper may not be applicable to the individual countries, but it can be applied for the cluster of these countries. Final recommendation is that energy efficiency shall be applied in electricity consumption and in other ways of using energy among the non-OECD countries in order to reduce the level of energy consumption in these countries. Similarly the level of economic output shall be increased to achieve low energy intensity. There should also be improvement in energy per-capita accessibility among the non-OECD nations.

\section{REFERENCES}

[1] J. Knox-Hayes, M. A. Brown, B. K. Sovacool, and Y. Wang, "Understanding attitudes toward energy security: results of a cross-national survey," Golbal Environmental Change, vol. 23, pp. 609-622, 2013.

[2] B. K. Sovacool and M. A. Brown, "Competing dimensions of energy security: an international perspective," Annual Review of Environment and Resources, vol. 35, pp. 77-108, 2010.

[3] IEA. Energy Balances of OECD Countries. [Online]. Available: http://scholar.google.com.hk/scholar

[4] L. Kitzing, C. Mitchell, and P. E. Morthorst, "Renewable energy policies in Europe: converging or diverging?" Energy Policy, vol. 51, pp. 192-201, 2012.

[5] I. Vassileva, E. Dahlquist, F. Wallin, and J. Campillo, "Energy consumption feedback devices' impact evaluation on domestic energy use," Applied Energy, vol. 106, pp. 314-320, 2013.

[6] I. Vassileva, F. Wallin, and E. Dahlquist, "Understanding energy consumption behavior for future demand response strategy development," Energy, vol. 46, pp. 94-100, 2012. 
[7] I. Vassileva, M. Odlare, F. Wallin, and E. Dahlquist, "The impact of consumers' feedback preferences on domestic electricity consumption," Applied Energy, vol. 93, pp. 575-582, 2012.

[8] N. Liu and B. W. Ang, "Factors shaping aggregate energy intensity trend for industry: energy intensity versus product mix," Energy Economics, vol. 29, pp. 609-635, 2007.

[9] J. E. Payne, "Survey of the international evidence on the causal relationship between energy consumption and growth," Journal of Economic Studies, vol. 37, pp. 53-95, 2010.

[10] S. Katircioglu, D. Cağ lar, and D. B. Kalmaz, "Trade, energy and growth in G7 countries," Actual Problems of Economics, vol. 139 pp. 346-358, 2013

[11] A. E. Akinlo, "Energy consumption and economic growth: evidence from 11 Sub-Sahara African countries," Energy Economics, vol. 30, pp. 2391-2400, 2008.

[12] M. A. Al-Iriani, "Energy-GDP relationship revisited: an example from GCC countries using panel causality," Energy Policy, vol. 34, pp. $3342-3350,2006$

[13] N. Apergis and J. E. Payne, "Energy consumption and economic growth in central america: evidence from a panel cointegration and error correction model," Energy Economics, vol. 31, pp. 211-216, 2009.

[14] S. Z. Chiou-Wei, C. F. Chen, and Z. Zhu, "Economic growth and energy consumption revisited - evidence from linear and nonlinear granger causality," Energy Economics, vol. 30, pp. 3063-3076, 2008.

[15] D. Joel, Energy and Population, Washington, D.C., 2004

[16] A. Mazur, "Population and environment," Coverage, vol. 15, pp. 371-378, 1994.

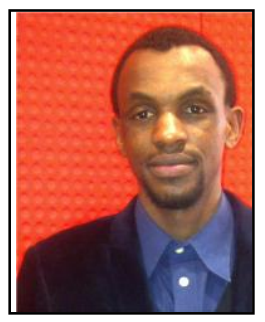

Ahmed Adamu was born in Katsina, Nigeria on $3^{\text {rd }}$ March, 1985 is currently a PhD student at Newcastle University, United Kingdom. Adamu did his master's degree in oil and gas economics from University of Dundee, United Kingdom in 2011. Adamu held an undergraduate degree in economics education from Bayero University, Kano, Nigeria in 2007. Ahmed Adamu is presently a University Lecturer at Umaru Musa Yar'adua University, Katsina, Nigeria. He was a classroom teacher of Economics at Government Senior Secondary School, Katsina, Nigeria up to 2011. He was an office assistant at National Inland Waterways Authority, Lokoja, Nigeria from 2008 to 2009. He is a member of International Association for Energy Economics (IAEE), Society for Petroleum Engineers (SPE), Teachers' Registration Council of Nigeria (TRCN), Academic Staff Union of Universities (ASUU), and Scottish Oil Club. He has research interest in economics and energy. He has the following publication history. 